\title{
The first record of the shore-fly Nostima semialata (Collin, 1913) for the fauna of Russia
}

\section{Первая регистрация мухи-береговушки Nostima semialata (Collin, 1913) в фауне России}

\author{
D.I. Gavrushin ${ }^{1}$, M.G. Krivosheina ${ }^{2}$ \\ А.И. Гаврюшин ${ }^{1}$, М.Г. Кривошеина ${ }^{2}$
}

'E-mail: dmitry_gavryushin@yahoo.com

${ }^{2}$ Institute of Ecology and Evolution, Russian Academy of Sciences, 33 Leninsky prospect, 119071 Moscow Russia. E-mail: dipteramarina@rambler.ru

Институт проблем экологии и эволюции РАН, Ленинский проспект 33, 119071 Москва Россия

\author{
KEY WORDS: Ephydridae, Nostima semialata, new record, Russia \\ КЛЮЧЕВЫЕ СЛОВА: Ephydridae, Nostima semialata, новая регистрация, Россия
}

ABSTRACT. The shore-fly Nostima semialata (Collin, 1913) is registered in Russia for the first time. The imago was found in late March in Naro-Fominsk, Moscow region. A key to genera of the subfamily Ilytheinae and a key to species of the genus Nostima Coquillett, 1900 of Russian fauna are provided.

РЕЗЮМЕ. Вид мухи-береговушки Nostima semialata (Collin, 1913) впервые регистрируется в фауне России. Имаго были найдены ранней весной в Наро-Фоминском районе Московской области. Приводится определительная таблица родов подсемейства Ilytheinae и определительная таблица видов рода Nostima Coquillett, 1900 фауны России.

The genus Nostima Coquillett, 1900 is a rather large genus of Ephydridae involving 51 species widely distributed in the world. However, the majority of species occurs in the New World (38 species) [Edmiston $\&$ Mathis, 2007]. Three species are known from the Palaearctic region, these are Nostima picta (Fallén, 1813) with 2 subspecies, picta picta (Fallén, 1813) and picta nigripes (Strobl, 1880), widespread in the Holarctic and Mexico, Nostima semialata (Collin, 1913), recorded from Great Britain, Germany, Hungary, Italy and Switzerland, and Nostima versifrons Miyagi, 1977, described from Japan (Honshu) and known only from the type locality. The only species of Nostima, N. picta, was previously known from Russia [Nartshuk, 1970].

Specimens of Nostima are uncommon in collections and in nature, and discovery of single specimens during sweeping is typical. Adults of Nostima, as a rule, occur in grassy habitats. As for larvae, it is reported that they develop in semiaquatic habitats and feed on blue-green algae [Foote, 1983].

Imagoes of most species of Nostima are very small, with body length about $1 \mathrm{~mm}$, yet very attractive hav- ing distinctive wing patterns and bright silvery-white or paler stripes of dense microtomentum.

The genus Nostima together with the genus Philygria Stenhammar, 1844, which were previously assigned to the tribe Philygriini, now are treated within the tribe Hyadinini, subfamily Ilytheinae [Edmiston \& Mathis, 2005].

Key to genera of Ilytheinae Cresson, 1943 (After EDMiston \& MAthis, 2005)

1. Posterior notopleural seta inserted near ventral margin of notopleuron and at about same level as anterior seta . 2

- Posterior notopleural seta inserted at conspicuously higher level than anterior seta..... 10

2. Vein $R_{2+3}$ short, costal section II about $1 / 3$ length of section III, and with a stump vein. A single, proclinate, fronto-orbital seta ....................... Parydroptera Collin

- Vein $\mathrm{R}_{2+3}$ long, costal section II at least half length of section III, lacking a stump vein. Usually a reclinate and proclinate fronto-orbital setae ................................... 3

3. Costa short, extended at most to slightly beyond vein $R_{4+5}$. Tergite 4 at least 3 times as long as tergite 5 Axysta Haliday

- Costa long, extended to vein M. Tergite 4 at most twice as long as tergite 5

4. Wing with vein $\mathrm{R}_{2+3}$ long; costal section II nearly 3 times as long as section III. Face flat or weakly carinate, not prominent medially. Flagellomere 1 rounded at apex above

- Wing with vein $\mathrm{R}_{2+3}$ short; costal section II less than twice length of section III. Face with low conical medial prominence. Flagellomere 1 usually angulate at apex above

5. Both an inner and outer vertical setae well developed; fronto-orbital setae usually moderately well to well developed, lateroclinate (Holarctic) .......... Pelina Haliday

- Only an inner vertical seta present, outer seta lacking; lacking well-developed fronto-orbital setae (Neotropical) …........................................ Pelinoides Cresson

7. Wing brown with about 14 distinct white spots Pseudohyadina Clausen 


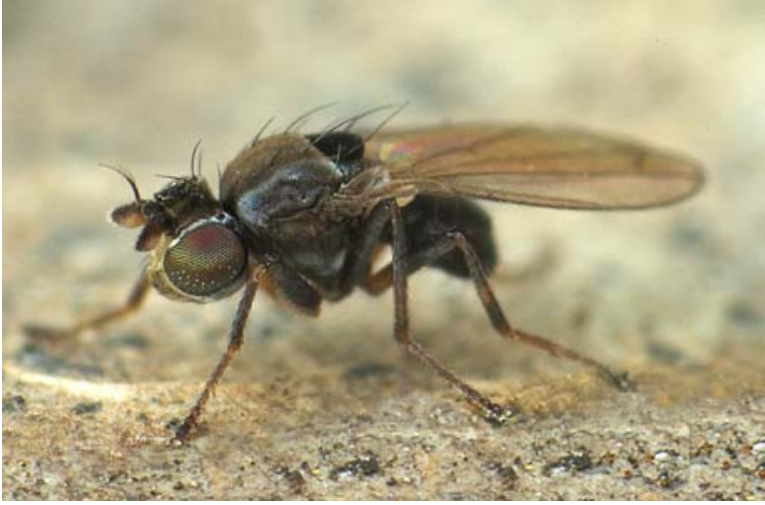

Fig. 1. Nostima picta, imago.

Рис. 1. Имаго Nostima picta.

- Wing unmarked or with at most faint spots or clouds at apex of vein R1 and on crossveins .....

.. 8

8. Tergite 4 from 1.3 to 2 times as long as tergite 5 , both conspicuously punctate. Inner vertical seta present, outer vertical seta absent. Lateral margin of scutellum not densely microtomentose, not appearing velvety ..... Lytogaster Becker

- Tergite 4 subequal in length to tergite 5 , neither conspicuously punctate. Usually both vertical setae present, if outer absent then lateral margin of scutellum densely microtomentose, appearing velvety

9. Dorsocentral seta 1. Lacking well-developed fronto-orbital setae Hyadina Haliday

- Dorsocentral setae 2. One well-developed fronto-orbital seta ......................... Parahyadina Tonnoir \& Malloch

10. Fronto-orbital setae either lateroclinate and inconspicuous or lacking; prescutellar acrostichal setae lacking ........ 11

- Fronto-orbital setae conspicuous, well developed, mostly reclinate or proclinate or both; prescutellar acrostichal setae present, well developed (Ilytheini Cresson)

11. Outer vertical seta lacking; fronto-orbital setae lacking Garifuna Mathis

- Both inner and outer vertical setae usually present; fronto-orbital seta present, sometimes reduced

12

12. Arista bare or minutely branched; 2 rows of facial setae. Presutural or sutural dorsocentral seta present Philygria Stenhammar

- Arista with short to long branches; 1 row of facial setae. Presutural or sutural dorsocentral seta lacking.....

.................................................... Nostima Coquillett

13. Dorsocentral setae $3(1+2)$.............. Donaceus Cresson

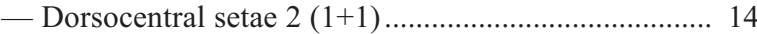

14. Vein $\mathrm{R}_{2+3}$ long, subparallel to $\mathrm{C}$; costal section II more than 2 times as long as section III ......... Ilythea Haliday

- Vein $\mathrm{R}_{2+3}$ short, running almost straight to $\mathrm{C}$; costal section II subequal to section III ............ Zeros Cresson

Key to species of Nostima Coquillett of Russia

1. Scutellum velvety-black, scutum brown. Bright silverywhite stripes of dense microtomentum present on frons along eyes and on thorax. Wings of normal length (Fig. 1) picta (Fallén)

- Scutellum and scutum unicolorous brown. No bright, only pale light stripes of dense microtomentum present

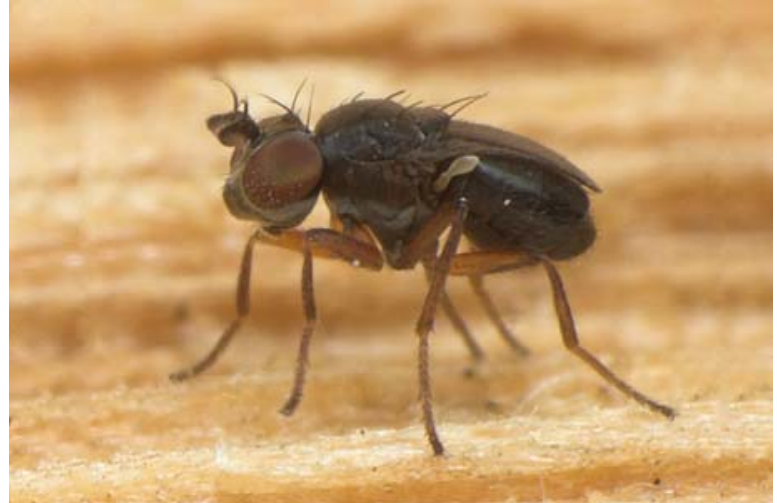

Fig. 2. Nostima semialata, imago.

Рис. 2. Имаго Nostima semialata.

on frons along eyes and on thorax. Wings shortened (Fig. 2) .................................... N. semialata (Collin)

Nostima semialata (Collin, 1913)

MATERIAL. 1 , RUSSIA: Moscow region, Naro-Fominsk, 28.III.2010, coll. D.I. Gavrushin (kept in Moscow Zool. Museum).

REMARKS. A single female was collected on March 28, 2010 at the outskirts of Naro-Fominsk, Moscow region, approximate coordinates $55.38939^{\circ} \mathrm{N}$, $36.773666^{\circ} \mathrm{E}$, elevation $182 \mathrm{~m}$. The day was mostly cloudy, with moderate to strong southern wind and temperature of around $+10^{\circ} \mathrm{C}$. The habitat was an edge of a pine forest with an old dirt track nearby, some of its parts representing more or less permanent small pools of stagnant water; there was still a lot of snow. Handfuls of dry plant material (twigs and leaves of Calamagrostis, pine needles, etc.) were carefully examined over a sheet of white paper, revealing adults of hibernating dipteran species typical for the region, those included Sphaeroceridae, Aphanotrigonum and Elachiptera (Chloropidae), Sciaridae, Mycetophilidae, Drosophilidae, Lonchoptera (Lonchopteridae), Geomyza tripunctata (Opomyzidae), Pachycerina (Lauxaniidae). The pictures were taken indoors under controlled lighting conditions with a piece of wood as a substrate. The fly was hopping instead of flying, and it's very probable it couldn't fly at all because of reduced wings.

\section{Literature}

Nartshuk E.P. 1970. Fam. Ephydridae - shore-flies // Key to insects of European part of the USSR. V. 5. P. 2. Leningrad: Nauka. P. 363-389.

Edmiston J.F., Mathis W.N. 2005. A revision of the New World species of the shore-fly genus Nostima Coquillett (Diptera: Ephydridae). Smithsonian Contributions to Zoology 623. P.1108.

Edmiston J. F., Mathis W.N. 2007. New Zealand species of the shore-fly genus Nostima Coquillett (Diptera: Ephydridae) // Zootaxa. 1661. P. 1-16.

Foote B.A. 1983. Biology and immature stages of Nostima approximata (Diptera: Ephydridae), a grazer of blue-green algal genus Oscillatoria // Proceedings of the Entomological Society of Washington. 85(3). P 472-484. 